\title{
Analisis Proses Perekrutan Karyawan Pada Hotel Discovery Kartika Plaza
}

\author{
Ni Putu Gili Padmayoni,Putu Indah Rahmawati \\ Undiksha
}

\begin{abstract}
Abstrak
Penelitian ini bertujuan untuk mengetahui: (1) proses perekrutan karyawan pada hotel Discovery Kartika Plaza (2) kendala-kendala yang dihadapi dalam proses perekrutan karyawan di hotel Discovery Kartika Plaza dan (3) strategi untuk mengatasi kendala-kendala dalam proses perekrutan karyawan di hotel Discovery Kartika Plaza. Penelitian ini merupakan penelitian deskriptif kualitatif yang mengambil lokasi di Hotel Discovery Kartika Plaza Bali. Subjek dalam penelitian ini adalah Human Resources Manager dan Human Resources Officer di Human Resources Department. Metode yang digunakan dalam penelitian ini adalah metode (1) Wawancara dan (2) dokumentasi. Hasil penelitian ini adalah (1) Proses rekrutmen karyawan pada Human Resources Department di Hotel Discovery Kartika Plaza sudah sesuai dengan ketentuan dan aturan yang berlaku di hotel. (2) Kendala-kendala yang dihadapi dalam proses rekrutmen karyawan adalah sedikitnya ketersediaan calon kandidat pada suatu posisi tertentu, banyaknya competitor dari hotel lain yang membutuhkan posisi yang sama. (3) Strategi untuk menangani kendala-kendala dalam proses perekrutan karyawan yaitu dengan memberikan hak dan kewajiban secara adil kepada dan selalu menjaga hubungan baik dengan talent-talent yang pernah bekerja sebelumnya di Hotel Discovery Kartika Plaza serta Human Resources Department dari perkumpulan hotel-hotel baik didalam maupun diluar bali
\end{abstract}

Kata Kunci : Proses rekrutmen, kendala, strategi

\begin{abstract}
This study aims to find out: (1) the process of hiring employees at Discovery Kartika Plaza hotel (2) constraints faced in the process of hiring employees at Discovery Kartika Plaza hotel and (3) strategies to overcome obstacles in the process of hiring employees in hotels Discovery Kartika Plaza. This research is a qualitative descriptive study that took place at the Discovery Kartika Plaza Bali Hotel. The subjects in this study were the Human Resources Manager and Human Resources Officer in the Human Resources Department. The method used in this study were method (1) Interview and (2) documentation. The results of this study are (1) The process of employee recruitment in the Human Resources Department at Discovery Kartika Plaza Hotel is in accordance with the rules and regulations that apply in the hotel. (2)The obstacles faced in the process of employee recruitment are the lack of availability of candidates in a particular position, the large number of competitors from other hotels who need the same position. (3)The strategy to deal with obstacles in the employee recruitment process is to provide rights and obligations fairly and to maintain good relations with talents who have worked previously at Discovery Kartika Plaza Hotel and the Human Resources Department of associations of hotels both inside and outside Bali
\end{abstract}

Keywords: Recruitment process, obstacles, strategy

\section{Pendahuluan}

Sumber Daya Manusia merupakan salah satu faktor yang sangat penting dalam bidang organisasi, maupun perusahaan, dimana salah satunya ialah perusahaan yang bergerak di bidang pariwisata khususnya industri perhotelan. 
Fokus utama Sumber Daya Manusia (SDM) adalah memberikan kontribusi atas suksesnya perusahaan. Agar produktifitas perusahaan berjalan lancar diperlukan karyawan yang sesuai dengan kebutuhan. Menurut Hasibuan, (2002), karyawan merupakan orang penjual jasa tenaga maupun pikiran dan mendapatkan kompensasi yang besarnya telah ditentukan sebelumnya. Sejalan dengan itu maka langkah awal yang menjadi kunci utama yaitu proses rekrutmen dan seleksi untuk merekrut tenaga kerja sesuai dengan kebutuhannya. Menurut Raymond A. Noe Dkk, (2011:266), Rekrutmen SDM didefiniskan sebagai praktik atau aktivitas apapun yang dijalankan oleh organisasi untuk mengidentifikasikan dan menarik para karyawan potensial. Sebagai salah satu hotel yang cukup terkenal dalam mengembangkan usahanya Hotel Discovery Kartika Plaza memerlukan beberapa orang karyawan baru sesuai dengan kebutuhan, mengingat pentingnya kebutuhan terhadap sumber daya manusia di jaman sekarang ini. Pada Hotel Discovery Kartika Plaza terdapat department Human Resources (Human Resources Department) yang mempunyai tugas dan tanggung jawab terhadap sumber daya manusia yang dibutuhkan oleh hotel. Dalam tugas dan tanggung jawab HRD terhadap sumber daya manusia salah satunya adalah perekrutan karyawan. Setiap hotel menerapkan standar operasional prosedur yang berbeda dalam kaitannya dengan rekrutmen karyawan, tak terkecuali Discovery Kartika Plaza Hotel, dimana selaku hotel dengan brand yang cukup besar tentu mempunyai standar operasional tersendiri dalam proses perekrutan karyawannya. Dari latar belakang tersebut penulis dapat merumuskan masalah sebagai berikut : (1) Bagaimanakah proses rekrutmen karyawan pada Human Resources Department di Discovery Kartika Plaza Hotel?, (2) apa saja kendala - kendala yang dihadapi dalam proses rekrutmen karyawan pada Human Resources Department Discovery Kartika Plaza Hotel?, (3) bagaimana strategi pihak Human Resources Department Discovery Kartika Plaza untuk mengatasi kendala - kendala dalam proses rekrutmen karyawan?. Adapun tujuan dari penelitian ini adalah untuk mengetahui proses rekrutmen karyawan pada Human Resources Department di Discovery Kartika Plaza Hotel, untuk mengetahui kendala - kendala yang dihadapi dalam proses rekrutmen karyawan pada Human Resources Department di Discovery Kartika Plaza Hotel, untuk mengetahui strategi pihak Human Resources Department Discovery Kartika Plaza untuk mengatasi kendala kendala dalam proses rekrutmen karyawan. 


\section{Kajian Pustaka}

\subsection{Konsep Human Resources Department (HRD)}

Berikut adalah pengertian dari Human Resources Department menurut para ahli: menurut Sofyandi, (2009:6) manajemen sumber daya manusia didefinisikan sebagai suatu strategi dalam menerapkan fungsi-fungsi manajemen yaitu planning, organizing, leading and controlling. Sedangkan menurut Bohlarander dan Snell, (2010:4) manajemen sumber daya manusia merupakan IImu yang mempelajari bagaimana memberdayakan karyawan dalam perusahaan, membuat pekerjaan, kelompok kerja, mengembangkan para karyawan yang mempunyai kemampuan.

\subsection{Fungsi dan Tujuan Human Resources Department}

Menurut Hasibuan (2011:21) fungsi dan tujuan manajemen sumber daya manusia antara lain : (1) fungsi manajerial yaitu perencanaan (planning), pengorganisasian (organizing), pengarahan (directing), pengendalian (controlling). (2) Fungsi Operasional yaitu pengadaan (procurement), pengembangan (development),kompensasi (compensation), integrasi (integration), pemeliharaan (maintenance), kedisiplinan, pemberhentian (separation).

Sedangkan tujuan dari manajemen sumber daya manusia adalah (1) untuk menentukan dan kuantitas karyawan yang akan mengisi semua jabatan dalam perusahaan, (2) menjamin tersedianya tenaga kerja masa kini maupun masa depan, sehingga setiap pekerjaan ada yang mengerjakannya, (3) menghindari terjadinya mismanajemen dan tumpang tindih dalam pelaksanaan tugas, (4) mempermudah koordinasi, integrasi, dan sinkronisasi, sehingga produktivitas kerja meningkat, (5) menghindari kekurangan dan atau kelebihan karyawan, (6) menjadi pedoman dalam menetapkan program penarikan seleksi, pengembangan, kompensasi, pengintegrasian, pemeliharaan, kedisiplinan, dan pemberhentian karyawan, (7) menjadi pedoman dalam melaksanakan mutasi (vertical atau horizontal) dan pensiun karyawan, (8) menjadi dasar dalam melakukan penilaian karyawan.

\subsection{Konsep Rekrutmen}

\subsubsection{Pengertian Rekrutmen}


Menurut Rivai (2009:148), "rekrutmen sebagai suatu rangkaian kegiatan yang dimulai ketika sebuah perusahaan memerlukan tenaga kerja dan membuka lowongan pekerjaan sampai mendapatkan calon yang diinginkan atau memenuhi kualifikasi sesuai dengan jabatan atau lowongan yang ada". Sementara menurut Hasibuan (2011:28), "rekrutmen adalah proses penarikan, seleksi, penempatan, orientasi dan induksi untuk mendapatkan karyawan yang efektif dan efisien membantu tercapainya tujuan perusahaan"

\subsubsection{Tujuan rekrutmen}

Menurut Rivai (2009:150) adalah "menerima pelamar sebanyak banyaknya sesuai dengan kualifikasi kebutuhan perusahaan dari berbagai sumber, sehingga memungkinkan akan terjaring calon karyawan dengan kualitas tertinggi dari yang terbaik. Sehingga diharapkan calon karyawan tersebut akan dapat menyelesaikan tugas dan pekerjaan yang dibebankan kepadanya dengan cara se-efisien dan se-efektif mungkin guna tercapainya tujuan".

Sedangkan tujuan dari rekrutmen karyawan menurut Samsudin (2009:81) adalah " mendapatkan calon karyawan yang memungkinkan pihak manajemen (recruiter) untuk memilih atau menyeleksi calon sesuai dengan kualifikasi yang dibutuhkan oleh organisasi atau perusahaan".

\subsubsection{Proses Rekrutmen}

Menurut Handoko (2008:69), proses perekrutan secara ringkas dapat dijelaskan dengan gambar berikut:

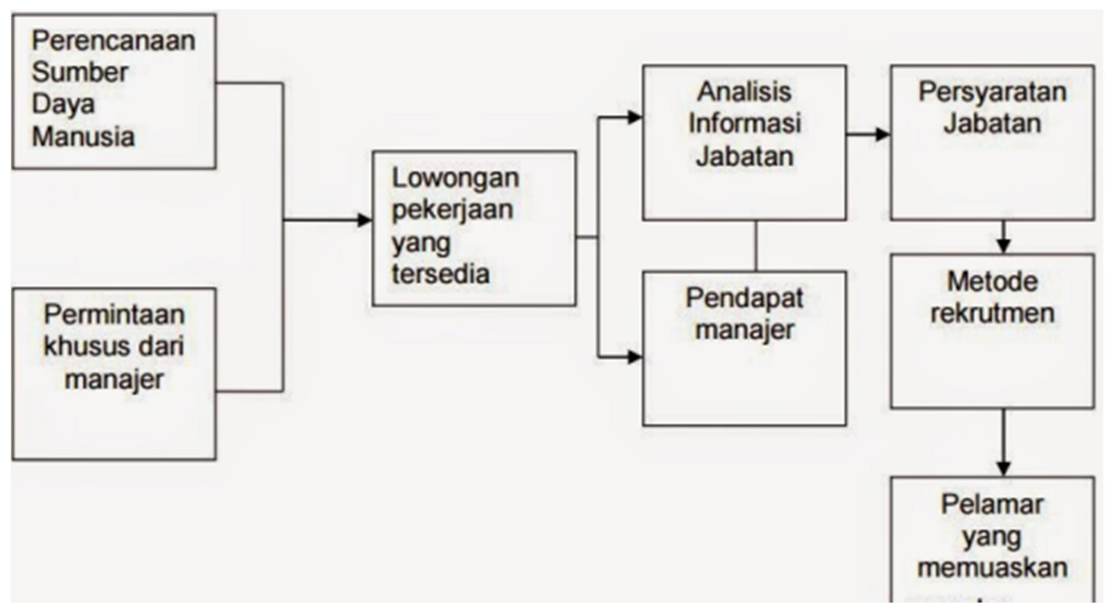

Gambar : Proses Rekrutmen menurut Handoko (2008:69) 
Menurut Handoko (2008:70), proses rekrutmen memiliki beberapa istilah popular: (1) Job Analysis (Analisis jabatan), (2) Job Description (Uraian Jabatan), (3) Job Specification (Persyaratan Jabatan), (4) Job Evaluation (Penilaian Jabatan), (5) Job Classification (Penggolongan Jabatan).

\subsubsection{Masalah dalam Proses Rekrutmen}

Menurut Siagian (2006:104) bahwa dalam menjalankan tugasnya mencari calon-calon pegawai, para pencari tenaga kerja suatu organisasi harus menyadari bahwa menghadapi berbagai kendala. Kendala-kendala ini muncul dari organisasi-organisasi yang bersangkutan, kebiasaan mencari tenaga kerja sendiri, dan faktor-faktor eksternal yang bersumber dari lingkungan dimana organisasi bergerak. (1) Faktor organisasional antara lain : kebijaksanaan promosi dari, kebijaksanaan tentang status kepegawaian, rencana sumber daya manusia. (2) kebiasaan mencari tenaga kerja pada biro personalia dimana biasanya ada satu bagian atau seksi yang bertugas melakukan rekrutmen penerimaan pegawai baru, para pegawai spesialis ini sudah mengetahui benar kriteria para pegawai yang diperlukan dalam rekrutmen tersebut untuk menyesuaikan dengan calon yang diajukan. (3) kondisi lingkungan eksternal, lingkungan eksternal organisasi harus selalu mendapat perhatian terutama dalam merekrut para pegawai baru. faktor-faktor eksternal yang perlu dipertimbangkan antara lain: tingkat pengangguran, kedudukan organisasi pencari tenaga kerja baru dengan memperhatikan organisai usaha sejenis sebagai saingan, proyek angkatan kerja, peraturan perundang-undangan dibidang ketenaga kerjaan sebagai faktor eksternal yang harus dipenuhi dan ditaati dalam rekrutmen, norma-norma etika yang berlaku bagi pencari tenaga dalam rangka rekrutmen, tuntutan tugas yang kelak akan dikerjakan para pekerja baru 


\subsection{Penelitian Terdahulu}

\begin{tabular}{|c|c|c|c|}
\hline NO & $\begin{array}{c}\text { Nama } \\
\text { Peneliti }\end{array}$ & $\begin{array}{c}\text { Judul } \\
\text { Penelitian }\end{array}$ & Hasil Penelitian \\
\hline 1 & $\begin{array}{l}\text { Gustina } \\
\text { (2013) }\end{array}$ & $\begin{array}{c}\text { Analisis Proses } \\
\text { Rekrutmen } \\
\text { Karyawan pada } \\
\text { Hotel } \\
\text { Pekanbaru }\end{array}$ & $\begin{array}{c}\text { Metode Perekrutan dengan sumber } \\
\text { internal untuk mengisi jabatan guna } \\
\text { menutupi keuangan Hotel yang } \\
\text { disebabkan karena sulitnya } \\
\text { mendapatkan tenaga kerja yang sesuai } \\
\text { dengan kebutuhan perusahaan, serta } \\
\text { yang memiliki kualitas yang baik } \\
\text { sehingga diperlukan latar belakang } \\
\text { pendidikan yang baik bagi para calon } \\
\text { tenaga kerja. }\end{array}$ \\
\hline 2 & $\begin{array}{l}\text { Kusumaningsi } \\
\text { h (2010) }\end{array}$ & $\begin{array}{c}\text { Prosedur } \\
\text { Penerimaan } \\
\text { Pegawai di } \\
\text { Hotel Lor In } \\
\text { Business Resort } \\
\text { \& Spa } \\
\text { Solo }\end{array}$ & $\begin{array}{l}\text { Dengan tetap mempertimbangkan } \\
\text { hokum, perusahaan harus merekrut } \\
\text { calon kandidat yang secara potensial } \\
\text { memenuhi syarat kualtas dan jumlah } \\
\text { yang memadai, menyadari pentingnya } \\
\text { sumber daya manusia sebagai aset } \\
\text { berharga dari perusahaan ,maka harus } \\
\text { diperhatikan sumber daya manusia } \\
\text { mulai dari perekrutan sampai dengan } \\
\text { penempatan }\end{array}$ \\
\hline
\end{tabular}

Penelitian ini berbeda dari penelitian sebelumnya dimana penelitian sebelumnya menggunakan jenis penelitian kuantitatif sedangkan penelitian kali ini menggunakan jenis penelitian kualitatif dengan tujuan untuk mengefektifkan hasil yang ingin dicapai, oleh karena itu penelitian ini penting untuk dilakukan guna membantu memberikan informasi mengenai proses rekrutmen di masa mendatang.

\section{Metode Penelitian}

\subsection{Rancangan Penelitian}

Penelitian ini menggunakan rancangan deskriptif kualitatif yang memaparkan data yang telah terkumpul melalui wawancara dan dokumentasi 
yang dilakukan secara langsung oleh peneliti kepada pihak hotel terkait data yang akan diperlukan pada penelitian ini. Data - data yang telah di dapat selama observasi dan wawancara akan ditarik suatu simpulan yang mana nantinya akan digunakan peneliti untuk memberi kesimpulan pada rumusan masalah yang telah peneliti tulis. Penelitian ini mengambil tempat di Discovery Kartika Plaza Hotel bagian HRD (Human Resources Department).

\subsection{Lokasi Penelitian}

Lokasi penelitian ini dilakukan di Discovery Kartika Plaza Hotel yang beralamat di Jalan Kartika Plaza, Kuta Selatan, Badung, Bali. Discovery Kartika Plaza dipilih sebagai lokasi penelitian dikarenakan penelitian ini memfokuskan pada proses rekrutmen karyawan pada hotel tersebut.

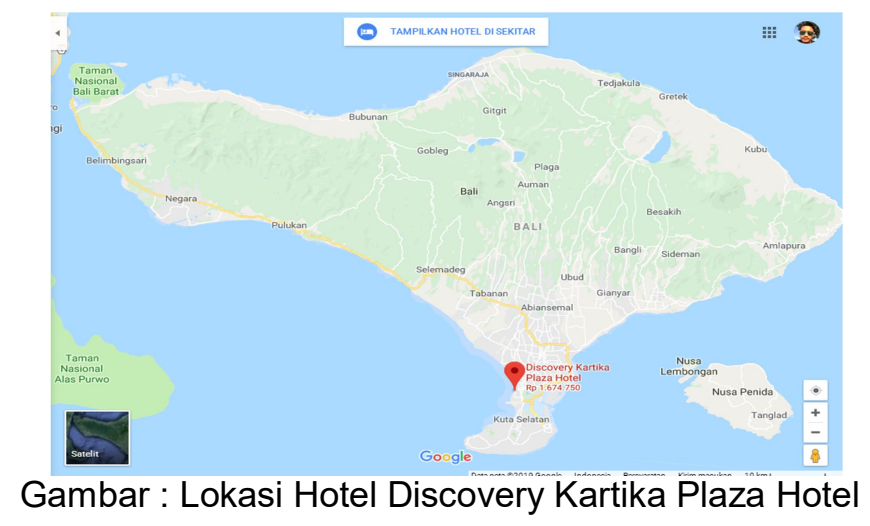

\subsection{Subjek \& Objek Penelitian}

Subjek penelitian yang dimaksud yaitu HRD (Human Resources Department), antara lain Human Resources Manager, Human Resources Officer serta pihak yang memiliki wewenang memberikan data yang bersangkutan terhadap penelitian ini. Human Resources Manager, Human Resources Officer dipilih sebagai subjek penelitian karena diharapkan dapat memberikan penjelasan yang sesuai dengan penelitian yang dilakukan. Objek penelitian ini adalah Proses perekrutan karyawan pada Hotel Discovery Kartika Plaza .

\subsection{Sumber Data}

Sumber data dalam penelitian ini adalah data primer dan data sekunder. Sumber data primer adalah data yang diperoleh dan dikumpulkan secara langsung dari subjek - subjek penelitian yang bersumber dari hasil observasi dan wawancara secara mendalam pada Human Resources Manager, Human 
Resources Officer. Sedangkan Sumber data sekunder adalah cara pengumpulan data tertulis yang diperoleh dengan cara mengumpulkan dokumen, foto-foto, catatan yang didapat, buku-buku pariwisata perhotelan dan internet maupun website hotel terkait mengenai masalah yang berhubungan proses perekrutan karyawan pada Human Resources Department di Hotel Discovery Kartika Plaza

\subsection{Metode Pengumpulan Data}

Dalam penyusunan tugas akhir ini menggunakan beberapa metode pengumpulan data dan instrumen untuk membantu peneliti dalam mengumpulkan data yang bermanfaat dan akurat, diantaranya : (1) wawancara, teknik pengumpulan data dengan melakukan tanya jawab langsung dengan responden dalam hal ini adalah pihak HRD (Human Resources Department), dan Human Resources Officer serta orang - orang yang berwenang terhadap permasalahan terkait dengan penelitian yang dilakukan. Selain itu dalam melakukan wawancara diperlukan adanya pedoman wawancara, buku catatan, voice recorder. Pedoman wawancara ini berfungsi untuk meluruskan percakapan ketika melakukan wawancara agar hal yang di bahas tidak jauh melebar dari materi, sedangkan buku catatan dan voice recorder berfungsi untuk mencatat dan merekam semua data dari wawancara yang di dapat oleh para narasumber untuk memudahkan dalam pengolahan data informasi terkait. (2) Dokumentasi, teknik pengumpulan data dengan cara mengumpulkan dokumen dan data seperti struktur organisasi hotel, dokumen HRD (Human Resources Department), dan fakta-fakta yang ditemukan sebagai acuan dalam penyelesaian penelitian ini serta informasi yang peneliti dapat dari website resmi Hotel Dalam hal ini digunakan kamera untuk mendapatkan gambar yang berkaitan dengan proses perekrutan karyawan serta laptop untuk mencari informasi di internet melalui website resmi Hotel.

\subsection{Metode Analisis Data}

Metode analisis data yang digunakan untuk keseluruhan data adalah deskriptif Kualitatif yaitu menguraikan dan memaparkan data yang telah diperoleh dari tempat penelitian yang berhubungan dengan proses perekrutan karyawan di Hotel. Tujuan metode ini adalah untuk menggambarkan secara sistmatis terhadap fenomena yang diteliti, Metode analisis data kualitatif menurut Miles dan Hubernam (1984) adalah sebagai berikut : (1) pengumpulan data, (2) reduksi data, (3) penyajian data, (4) 
kesimpulan dan verifikasi data.

\section{Hasil Penelitian dan Pembahasan}

\subsection{Gambaran Umum Lokasi Penelitian}

Discovery Kartika Plaza terletak di Kuta, dekat dengan Bandara Ngurah Rai Internasional. Memilki 318 kamar dan 6 villa. Discovery Kartika Plaza Hotel di Jalan Kartika Plaza, PO BOX 803061, Bali. Indonesia. Discovery Kartika Plaza Hotel adalah hotel pertama yang ada didaerah Kuta Bali, ada sejak tahun 1979 bernama Kartika Plaza Beach Hotel, Bali. Dibawah kepemilikan Induk Koperasi Angkatan Darat (INKOPAD) dan dikelola oleh salah satu anak perusahaan PT. Wisma Kartika. setelah renovasi Kartika Plaza Beach Hotel Bali, nama ini diubah menjadi Discovery Kartika Plaza Hotel.

\subsection{Hasil Penelitian}

\subsubsection{Proses rekrutmen karyawan pada Human Resources Department di Discovery Kartika Plaza Hotel}

Berdasarkan kepada hal tersebut menurut informasi dari HRD ( Human Resources Department) Discovery Kartika Plaza Hotel, ada beberapa proses rekrtument karyawan yang diterapkan oleh manajemen hotel, yaitu : (1) Perencanaan/Planning, pihak hotel menegaskan bahwa proses rekrutmen terjadi karena adanya turn over seperti jika ada karyawan yang resign, pensiun, pensiun dini, meninggal, Hotel merekrut karyawan jika hotel memang sedang membutuhkan karyawan, kemudian jika suatu department membutuhkan karyawan maka harus melalui persetujuan General Manager. Selain itu rekrutmen karyawan harus sesuai dengan budget yang disediakan hotel, dimana department yang membutuhkan karyawan harus mengisi employee requisition. Setelah semua sudah mendapat persetujuan, maka HRD bertugas untuk membuat Advertising atau pengumuman perihal lowongan kerja yang dibutuhkan. (2) Pengorganisasian/Organizing, setelah adanya permintaan kebutuhan karyawan maka HRD akan membuat advertising, hal ini sendiri dilakukan dengan dua cara yaitu ekstrenal dan internal. Untuk yang internal, HRD terlebih dahulu akan menginformasikan lowongan didalam manajemen hotel sendiri bahwa salah satu department di hotel memerlukan karyawan. Kemudian untuk yang eksternal yaitu proses perekrutan karyawan dengan menginformasikan melalui website hotel, social media milik hotel ataupun 
menyebarkan digrup Human Resources di dalam maupun diluar Bali, seperti digrup Hotel Human Resources Managers Association (HHRMA) Bali. Ketika hotel berniat merekrut karyawan di posisi yang membutuhkan spesifikasi tertentu, maka HRD akan melakukan head hunting, dimana HRD sudah mengetahui siapa orang yang dibutuhkan dalam sebuah posisi tersebut melalui informasi dari Head Hunter yaitu suatu lembaga, perorangan maupun organisasi yang mencari dan menempatkan orang berkualifikasi atau professional di suatu posisi tertentu dalam perusahaan. Kemudian ada juga yang dinamakan "rekomendasi" misalkan sebagai contoh seorang manager disebuah department yang membutuhkan karyawan pernah memiliki anak didik atau trainee yang dirasa mampu dan pantas berada diposisi tersebut maka ia memiliki kesempatan untuk merekomendasikan orang tersebut ke HRD, lalu calon karyawan yang berhasil memenuhi persyaratan akan diminta untuk mengisi application form. Calon kandidat yang sedang dalam proses penilaian akan dinilai oleh HRD, General Manager dan HOD ( Head Department), selain itu HRD juga akan melakukan reference check dari hotel tempat bekerja calon kandidat sebelumnya. Untuk interview di Discovery Kartika Plaza ada 3 macam, yaitu cek kesehatan, psikotes atau tes mental dan kejiwaan, kemudian interview "Pamen". Khusus di Discovery Kartika Plaza interview dengan "Pamen" bertujuan untuk mengetahui wawasan kebangsaan dan seberapa nasionalisnya calon kandidat tersebut Jika semua sudah sesuai dengan persyaratan dan calon kandidat memiliki SKCK ( surat keterangan catatan kepolisian) yang baik ,kemudian akan dilanjutkan ke proses Hiring atau mempekerjakan. Sebelum proses Hiring itu dimulai HRD terlebih dahulu akan membuat LOI ( letter of intent) yaitu perjanjian antara kedua belah pihak yg mengikat secara hukum. (3) Pengarahan/Directing, setelah semua persyaratan sudah selesai dan perjanjian kontrak kerja sudah disepakati antara kedua belah pihak, maka HRD kemudian akan melakukan orientasi atau pengenalan lingkungan hotel, kemudian induksi atau pengenalan ke masing masing department di hotel. (4) Pengawasan/Controlling, selama masa awal bekerja, dalan surat perjanjian juga berisi keterangan bahwa karyawan akan mengalami masa evaluasi dan percobaan selama 3 bulan, kemudian jika penilaian karyawan tersebut baik, maka selanjutnya karyawan dapat dikontrak selama 1 tahun pertama.

\subsubsection{Kendala - kendala yang dihadapi dalam proses rekrutmen karyawan pada Human Resources Department Discovery Kartika Plaza Hotel}


Pada saat merekrut calon kandidat, sebelumnya akan dilihat dari seberapa susah posisi, seberapa tinggi posisi, dan seberapa unik posisi tersebut karena semakin susah dan unik posisi tersebut maka ketersediaan sumber daya manusia nya juga terbatas. Selanjutnya adalah banyaknya kompetitor dari Hotel lainnya, kurangnya komitmen daripada calon kandidat dan yang terakhir adalah penilaian sosial terhadap brand hotel yang bersangkutan

\subsubsection{Strategi pihak Human Resources Department Discovery Kartika Plaza untuk mengatasi kendala - kendala dalam proses rekrutmen karyawan}

Hubungan kerjasama yang baik dengan talent talent Discovery Kartika Plaza Hotel , talent yang dimaksud adalah mantan anak trainee, mantan daily worker yang sebelumnya pernah bekerja di Discovery Kartika Plaza Hotel. Selain itu, selalu berhubungan baik dengan HRD lainnya, ini bertujuan untuk mencari rekomendasi calon kandidat yang sesuai ketentuan, kemudian memastikan segala hak dan kewajiban karyawan dipenuhi dan diberikan secara adil sehingga karyawan bahagia dan memberikan citra baik saat diluar mengenai hotel, dan yang terakhir membangun social community dengan lingkungan sekitar hotel.

\subsection{Pembahasan}

\subsubsection{Proses Rekrutmen Karyawan pada Human Resources Department di Discovery Kartika Plaza Hotel}

Berdasarkan hasil penelitian oleh Menurut Handoko, (2018) tentang “Manajemen Personalia dan Sumber Daya Manusia”, proses rekrutmen memiliki beberapa istilah popular: (1) Job Analysis (Analisis jabatan), prosedur untuk menentukan tanggung jawab dan persyaratan. (2) Job Description (Uraian Jabatan), dimaksudkan untuk memberikan keterangan tentang fakta - fakta yang penting dari jabatan yang diperlukan. (3) Job Specification (Persyaratan Jabatan) catatan mengenai syarat - syarat minimum yang harus dimiliki untuk menyelesaikan suatu pekerjaan dengan baik. (4) Job Evaluation (Penilaian Jabatan), kegiatan yang dilakukan guna membandingkan nilai dari suatu jabatan dengan nilai dari jabatan dengan jabatan lainnya. (5) Job Classification (Penggolongan Jabatan), pengelompokan jabatan - jabatan yang memiliki nilai yang sama. 
Berdasarkan hasil penelitian dari Handoko, (2008) tentang 'Manajemen Personalia dan Sumber Daya Manusia' serta pendapat dari pihak Assistant Human Resources Manager Discovery Kartika Plaza Hotel , maka dapat disarankan bahwa Human Resources Department dapat menjalankan proses rekrutmen karyawan sesuai kebutuhan dengan menetapkan prosedur, aturan, serta ketentuan yang diberlakukan oleh manajemen hotel, sehingga nantinya pada saat proses rekrutmen karyawan berjalan dengan lancer dan adil agar harapan dari manajemen hotel untuk bisa mendapatkan calon karyawan yang sesuai karakteristik hotel dapat terlaksana dengan baik.

\subsubsection{Kendala - Kendala yang dihadapi dalam Proses Rekrutmen Karyawan pada Human Resources Department Discovery Kartika Plaza Hotel}

Berdasarkan penelitian oleh Hasibuan, (2010) tentang 'Manajemen Sumber Daya Manusia' terdapat beberapa kendala dalam proses rekrutmen, diantaranya : (1) kebijakan dari perusahaan megenai gaji, kompensasi, (2) persyaratan jabatan dimana semakin banyak persyaratan maka semakin dikit jumlah pelamar, (3) metode pelaksanaan rekrutmen, (4) kondisi pasar tenaga kerja, (5) solidaritas perusahaan, (6) kondisi lingkungan. Dari hasil penelitian Hasibuan, (2010) tentang 'Manajemen Sumber Daya Manusia' dan pendapat daripada Assistant Human Resources Manager Discovery Kartika Plaza Hotel dapat disarankan juga kepada Human Resources Department Discovery Kartika Plaza Hotel ketika mengahadapi kendala - kendala yang sudah umum terjadi pada saat proses rekrutmen karyawan, semua kendala dapat diatasi dengan strategi dan penanganan yang tepat sesuai dengan ketentuan yang berlaku dihotel, hal tersebut sangat berguna untuk memperbaiki jika ada kendala baik dari internal maupun eksternal, teknis maupun nonteknis.

\subsubsection{Strategi pihak Human Resources Department Discovery Kartika Plaza untuk Mengatasi Kendala - Kendala Dalam Proses Rekrutmen Karyawan}

Berdasarkan penelitian yang dilakukan oleh Licen Indahwati Darsono, (2002) tentang 'Transformasi Organisasional dan MSDM : Hambatan dan Implikasinya pada Rekrutmen dan Seleksi' ada beberapa strategi yang digunakan untuk mengatasi kendala-kendala dalam proses rekrutmen adalah : 
(1) dapat memahami budaya dan karakteristik hotel yang bersangkutan sebelum melakukan proses rekrutmen dengan tujuan memberikan informasi kepada calon kandidat, (2) memahami karakterstik karyawan maupun calon karyawan dari berbagai tingkatan dengan tujuan dapat memberlakukan aturan yang diterima oleh calon karyawan, (3) melakukan hubungan baik dengan lingkungan baik dalam maupun luar hotel, hal ini bertujuan untuk meciptakan hubungan baik antara hotel dan masyarakat.

\section{Penutup}

Berdasarkan hasil peneltian mengenai Proses Perekrutan Karyawan pada Hotel Discovery Kartika Plaza, maka dapat ditarik kesimpulan terkait mengenai penelitian tersebut, sebagai berikut :

1. Prosedur terkait proses rekrutmen karyawan merupakan awal dari berjalannya sebuah hotel, maka sangat penting bagi Human Resources Department untuk mampu melakukan proses rekrutmen yang sesuai dengan standar operasional prosedur yang ditentukan manajemen hotel.

2. Kendala-kendala yang terjadi saat proses rekrutmen karyawan oleh pihak Human Resources Department disebabkan oleh keterbatasan jumlah kandidat dalam suatu posisi, kemudian banyaknya competitor dari hotel lain yang membutuhkan posisi yang sama, komitmen daripada calon kandidat, dan penilaian social dari lingkungan terhadap brand dari hotel.

3. Strategi mengatasi kendala-kendala yang terjadi dalam proses rekrutmen karyawan oleh pihak Human Resources Department adalah dengan memastikan semua hak dan kewajiban karyawan terpenuhi agar nanti nya image hotel yang disampaikan keluar oleh karyawan mendapat respon positif, membangun social community yang baik dengan lingkungan, serta menjalin hubungan baik dengan talent-talent hotel dan Human Resources lain di dalam maupun luar Bali.

\section{Daftar Pustaka}

Anonim.2014.Pengertian, Fungsi, dan Tugas Penting Human Resources Department. Tersedia pada https://www.dosenpendidikan.com/pengertianfungsi-dan-tugas-penting-hrd-dalam-perusahaan diakses pada 12 maret $\underline{2019}$.

Satria,Ase.2015. Tujuan dan Fungsi Manajemen Sumber Daya Manusia Menurut Para ahli, Tersedia pada https://www.materibelajar.id/2015/12/tujuan-danfungsi-manajemen-sumber-daya.htm/\# diakses pada 12 maret 2019 
Anonim. Definisi Rekrutmen. Tersedia pada http://eprints.polsri.ac.id/2434/3/BAB\%20Il.pdf, diakses pada 12 maret 2019

Trianto,Rikie.2014. Pengertian Proses Rekrutmen dan Seleksi . Tersedia pada http://rikietrianto.blogspot.com/2014/06/pengertian-proses-rekrutmen-danseleksi.html, diakses pada 14 maret 2019

Anonim, Rekrutmen Karyawan, Tersedia pada https://library.binus.ac.id/eColls/eThesisdoc/.../2015-1-00189 MN\%20Bab2001.doc diakses pada 14 maret 2019

Anonim, Kendala Proses Rekrutmen , Tersedia Pada https://repository.widyatama.ac.id/xmlui/bitstream/handle/123456789/.../Ba b\%202.pdf diakses pada 20 maret 2019

Anonim. Peta lokasi hotel discovery kartika plaza, Tersedia pada https://www.bing.com/maps?q=discovery+kartika+plaza\&FORM=HDRSC4 diakses pada 12 april 2019.

Sahid,Rahmat.2011.analisis data kualitatif miles dan huberman, tersedia pada http://sangit26.blogspot.com/2011/07/analisis-data-penelitian-kualitatif.html diakses pada 12 april 2019

Zakiyudin.2012. Fungsi Manajemen Sumber daya Manusia, Tersedia Pada http://ais-zakiyudin.blogspot.com/2012/06/hani-handoko-normal-0-falsefalse-false.html diakses pada 10 Mei 2019

Anonim, Kendala Dalam Proses Rekrutmen menurut para ahli. Tersedia pada https://www.pahlevi.net/pengertian-rekrutmen/diakses pada 12 Mei 2019

Darsono. 2002. Transformasi Organisasional dan MSDM : Hambatan dan Implikasinya pada Rekrutmen dan Seleksi, Tersedia pada

http://jurnalmanajemen.petra.ac.id/index.php/man/article/view/15624

diakses pada 17 Mei 2019 